\title{
OS ANNALES E SUA CONTRIBUIÇÃO PARA A TEORIA E METODOLOGIA DA HISTORIA EM EDUCAÇÃO DO CAMPO
}

\author{
Marcos José de Araujo Caldas ${ }^{1}$ \\ Mônica de Souza Nunes Martins ${ }^{2}$
}

\begin{abstract}
Resumo:
Este artigo é resultado da experiência do ensino de História para o curso superior de Educação no campo, ocorrido em 2011, na Universidade Federal Rural do Rio de Janeiro. O artigo foi dividido em duas partes: a primeira é uma breve e geral da reflexão da ciência histórica, de suas linhas constitutivas, em especial a partir da contribuição do pensamento dos Annales sobre tempo e espaço, fundamentais para a construção da ciência histórica no século $\mathrm{XX}$; a segunda parte do artigo se dedica mais detidamente às especificidades do ensino de História, mais especialmente no que diz respeito à teoria e à metodologia em História, trazendo o que pensamos ser as linhas mestras para a reflexão do ensino de História para a Educação do Campo na Universidade.
\end{abstract}

Palavras chaves: Annales, Ensino de História, Educação do Campo.

\begin{abstract}
:
This article is the result of a teaching experience in History to the Rural High Education course which occurred in 2011 at Universidade Federal Rural do Rio de Janeiro. The article was divided into two parts: the first one is a brief and general reflection towards the historical science, its constitutive guidelines, specially starting from the contribution to the thought of Annales concerning time and space which are fundamental to the historical science in the twentieth century; the second part of the article is devoted more closely to the teaching of history specificities, specially when it comes to the theory and methodology regarding history, coming up with what we think are the guidelines to the teaching of history reflection to the Rural Education at the University.
\end{abstract}

Key words: Annales, Teaching's History, Rural Education.

\section{Introdução:}

Em 2011, iniciamos o trabalho com a turma de Licenciatura em Educação do

Campo da UFRRJ com a disciplina Formas de desenvolvimento do capitalismo,

\footnotetext{
${ }^{1}$ Professor Adjunto III do Departamento de Historia e Economia da Universidade Federal Rural do Rio de Janeiro (UFRRJ). Doutor em Filosofia pela Rheinische Friedrich Wilhelms Universität Bonn. E-mail: marcos.caldas@gmail.com.

${ }^{2}$ Professora Adjunta do Departamento de Historia e Economia da Universidade Federal Rural do Rio de Janeiro (UFRRJ). Doutora em Historia Social pela Universidade Federal do Rio de Janeiro (UFRJ). E-mail: monic1922@gmail.com.
} 
disciplina ministrada para todos os estudantes do curso. Em 2012 foi ministrada a disciplina Teoria e Metodologia da História para aqueles que optaram pelo módulo de Ciências Sociais. Descreveremos aqui um pouco da experiência do trabalho com as turmas, focando na importância do curso para a universidade e na articulação fundamental entre a universidade e o aprendizado com os movimentos sociais.

Apesar da referência à educação do campo como foco para a abordagem do trabalho neste programa, a composição dos estudantes é bastante diversa. Assim temos a integração entre estudantes oriundos de movimentos sociais diversos, rurais e urbanos, dialogando, integrando e trocando experiências. Essa troca de experiências se reflete de forma frutífera em sala de aula, na permanente articulação dos temas em debate com as experiências vividas e com o compartilhamento delas entre os estudantes. Como ponto de intersecção entre eles destacam-se a disciplina e a organização da turma para as aulas e a valorização daquele espaço como uma articulação fundamental para os elos entre suas vivências políticas, suas perspectivas de luta e suas esperanças.

Pensar as transformações que levaram ao surgimento do capitalismo nos remete ao debate proposto por Ellen Wood em A origem do capitalismo (WOOD, 2001), onde a autora enfatiza a importância da desnaturalização do entendimento sobre o surgimento do capitalismo. A proposta do debate com uma historiografia abrangente levou a autora à reflexão sobre as relações entre o rural e o urbano no surgimento do capitalismo, contestando a visão predominante de que as relações mercantis foram decisivas para o surgimento do capitalismo nas cidades. Ela destacou que o que distingue o capitalismo do pré-capitalismo não é a oposição rural e urbano, mas a posse dos meios de produção pelos camponeses e a expropriação destes através dos mecanismos de domínio de classe que se dão em determinado momento histórico. E ela desmistifica exatamente isso, abandonando a oposição rural $x$ urbano para pensar o desenvolvimento das formas capitalistas de produção como fruto de transformações que se originam nas relações com a propriedade da terra.

Desta forma, uma ponte proposta por nós devia remeter os estudantes a um debate pouco explorado: o diálogo entre a visão sobre um capitalismo consolidado na sociedade atual com o seu processo de formação e consolidação, através do tempo; a possibilidade de um debate entre a vida e a teoria onde ambos se apresentassem em sua intimidade e proximidade. Trazer a teoria à vida é obrigação do professor e uma meta fundamental e permanente do trabalho em sala de aula. 
Em 2012 essa experiência do trabalho com a LEC (Licenciatura em Educação do Campo) teve continuidade com a disciplina Teoria e Metodologia em História. As aulas foram propostas de forma a articular o debate no campo da teoria e da metodologia em História, pontuando esses aspectos no processo de construção do conhecimento histórico ao longo dos séculos XIX e XX. Neste sentido, buscou-se também articular a reflexão sobre a abordagem teórica com as pesquisas propostas pelos estudantes, o que acabou se refletindo num riquíssimo debate sobre a importância e a aplicabilidade das discussões teóricas na pratica da pesquisa.

\section{A História e a Vida}

Dos porões da prisão nazista de Montluc, Marc Bloch nos deixou o registro de uma percepção da História até hoje tomada como referência no campo da historiografia, o livro Apologia da História ou o ofício do Historiador (BLOCH, 2001) $)^{3}$. Seu registro comprometido e militante revelava mais do que a erudição impressionante de um texto elaborado sem acesso às referências bibliográficas: o texto de Bloch expressa o compromisso com a vida, com a transformação e com a certeza de que a teoria e o método de trabalho do historiador exercem essa função norteadora, orientadora para as ações da pesquisa, mas, fundamentalmente, para se pensar e agir no mundo, a união entre reflexão e ação (DOSSE, 1992, p. 62). É o relato da observação apurada de que o papel do historiador (e por que não de todo o pesquisador?) deve ser aquele de "saber falar, no mesmo tom, aos doutos e aos estudantes" (Idem, Introdução).

Tomamos este ensaio que nos foi presenteado por Bloch como ponto de partida para uma reflexão sobre a História e sua relação com o tempo vivido e com aquilo com o que nos comprometemos. A teoria da História representa elemento central dessa percepção de mundo a ser formulada pelo historiador e disso falaremos mais adiante. A reflexão e a postura do pesquisador diante do objeto pesquisado refletem o olhar dele sobre a vida, sobre seu papel na sociedade, sobre a concepção de ciência que professa, sobre o que entende e como percebe a vida e as transformações e/ou continuidades sociais.

\footnotetext{
${ }^{3}$ O livro foi composto entre os anos 1941 e 1943, mas publicado apenas em 1949. Nesta época, Bloch entrara para o movimento "Franc Tireur", e enviado como delegado, representado este mesmo movimento, para o MUR (Movimentos Unidos da Resistência), para a liberação de Lyon. Em 8 de março de 1944 é preso pela Gestapo e encarcerado na prisão de Montluc. Em 16 de junho deste mesmo ano, Bloch, com 29 outros presos, foi levado para Sans-Didier-de-Formans, cerca de 30 quilômetros de Lyon, e fuzilado.
} 
O princípio da História como um seqüencial recorte de fatos, em busca de uma veracidade abstrata, circunscrita ao trabalho exaustivo com fontes documentais escritas, se constituiu em um eixo fundamental das críticas de Marc Bloch, de Lucien Febvre e de uma geração de historiadores que traçaram um profícuo caminho para a construção de um novo paradigma a partir da historiografia francesa (Cf. BURKE, 1997). Para uma crítica dos Annales e a discussão sobre a questão da 'Escola' dos Annales (Cf. STOIANOVICH, 1976). Esse paradigma foi elaborado mediante uma batalha intelectual contra uma perspectiva da História consolidada ao longo do século XIX, caracterizada grosso modo como "História tradicional" ou adepta do positivismo. Esse novo combate foi marcado pela produção intelectual do grupo ligado à Revista dos Annales ${ }^{4}$.

O novo prisma metodológico oferecido pela elaboração da "História como problema" pelos Annales refletia a preocupação também com a problematização da vida, rejeitando as "verdades" dos documentos ou a naturalização dos fatos oferecidos pelas fontes. Estavam postas na mesa do historiador as questões e hipóteses de pesquisa, aquelas que deveriam levar os pesquisadores às fontes: entendendo que elas não falam por si mesmas; propunha-se que as fontes, em suas múltiplas formas, fossem provocadas, indagadas, desafiadas. As questões e hipóteses exerceriam assim uma função norteadora no método de trabalho do pesquisador, na medida em que ele passasse a estabelecer um diálogo com as fontes, onde estas ganhariam dinamismo em sua interlocução com as questões construídas pelo tempo, pela sociedade e pelas perspectivas do historiador.

Assim, o "problema" ou as questões de pesquisa tornam-se o eixo a partir do qual a própria pesquisa circula e se justifica, opondo-se a uma sequencia cronológica e factual como centrais para a elaboração de um recorte histórico de pesquisa; como Jacques Le Goff definiu “a Nova História é uma história-problema". Encontrar um "problema” não seria certamente uma questão nova no trabalho de historiadores, o que se tornava novo nessa corrente historiográfica era a insistência em perceber a "problematização da pesquisa", um objeto central e antagônico à perspectiva factual da escola historicista.

\footnotetext{
${ }^{4}$ A Revista chamada de Annales d'Histoire Économique e Sociale (o nome atual é Revue Annales. Histoire et Sciences Sociales) é uma revista trimestral e tem o seu primeiro tomo publicado em 1929. Os números da primeira década da revista estão disponíveis em: http://gallica.bnf.fr/ark:/12148/cb34414997g/date.r=.langEN. Os números correspondentes aos anos de 1929-1932, 1939-1941 e 1943-2002, encontram-se em www.persee.fr.
} 
O ofício do historiador ao questionar a fonte é nela projetar também as perguntas pertinentes para sua vida, de acordo com as preocupações da sociedade onde vive e, irrefutavelmente, no seu tempo, tecendo um fino e rigoroso campo de trabalho que caracteriza a produção intelectual. Ao formular questões o historiador abre a janela de inquietações políticas, morais, éticas e científicas, tornando a pesquisa um campo de ação que dialoga e interage com a vida e com a sua percepção de mundo, sem abrir mão do rigor científico e da metodologia e técnica de trabalho com as fontes.

Neste sentido o passado ganha dinamismo e cores vivas e se torna - ele mesmo parte inerente do presente. Ou seja, a História passa a ser entendida como reescrita, como uma construção do tempo presente, onde o olhar e o método de trabalho do historiador atuam para elaborar uma análise sobre o passado, calcado nas referências, preocupações e nas indagações da contemporaneidade. O presente dialoga com o passado, numa dialética construção de perspectivas e memórias que não prescindem do olhar construído pelo historiador. A História, contestada como uma "ciência do passado" se torna campo fecundo de estudos sobre a sociedade no tempo, uma janela onde o tempo presente se transforma também em objeto da reflexão histórica.

Este novo entendimento que permeava a problematização do objeto histórico obrigava também o pesquisador a sair em campo em busca de outros diálogos, com outras áreas de conhecimento, tornando o trabalho interdisciplinar uma marca da nova percepção sobre a construção do conhecimento acadêmico, mais particularmente, do conhecimento histórico. A História se permitia flertar com os outros campos das ciências sociais e humanas, numa intersecção de saberes e na utilização de conceitos e metodologias pertinentes a outros campos de conhecimento.

Fernand Braudel conclamou as ciências sociais ao diálogo em Escritos sobre a História (BRAUDEL, 2007), apontando um esmagamento das "ciências do homem" ao buscarem as fronteiras que as separavam mais do que os traços que as aproximavam, ainda que apontasse um "interesse nessas querelas e nessas recusas", afinal "O desejo de cada um se afirmar contra os outros está forçosamente na origem de novas curiosidades: negar outrem, já é conhecê-lo" (Idem, p. 42). Apresenta-se com Braudel a fina teia tecida pelo tempo histórico, matéria prima fundamental do historiador no seu ofício, onde o tempo se apresenta em suas múltiplas facetas cronológicas atendendo às expectativas e projeções da sociedade, repartindo-se em temporalidades afeitas à durabilidade das ações no tempo e ao tempo das ações humanas: a curta, a média e a longa duração. Para Braudel a História se traduz como uma "dialética da duração; por 
ela, graças a ela, é estudo do social, de todo o social, do passado, e, portanto, também do presente, um e outro inseparáveis" (Idem, p. 98).

O tempo foi, sem dúvida, o recorte epistemológico fundamental da consolidação dessa nova percepção sobre o ofício: o tempo histórico compreendido pela Nouvelle Histoire, a partir dos anos 1930, contrapunha-se as influências da teologia ou da filosofia e se propunha a um diálogo mais profundo com as ciências sociais, recusando- se às perspectivas teleológicas (REIS, 2008), a uma perspectiva de uma História linear, progressiva e, portanto, irreversível. Esse caminho desbravado posteriormente por Braudel era um dos passos de toda uma reflexão construída onde o tempo histórico imprimia-se da necessidade de conhecer as condições do "fazer histórico", no entendimento das conjunturas, das estruturas, das permanências, das transformações, das resistências e das particularidades do cotidiano.

Portanto,

\begin{abstract}
O novo tempo histórico consiste em uma hipótese contrária a do tempo filosófico: o tempo não é progressivo, mas pluridirecionado; não é global, mas múltiplo. (...) Enquanto imanente aos processos objetivos, o tempo histórico revela antes sua pluralidade, sua multiplicidade, a sua descontinuidade, as suas assimetrias, as suas irreversibilidades particulares e jamais a unidade total. Não se tem mais a unidade, mas a diversidade. (Idem, 31).
\end{abstract}

Esse nova percepção do tempo histórico só pode se concretizar no nível do fazer histórico a partir de uma nova compreensão sobre os métodos e técnicas de pesquisa, na ampliação da compreensão sobre o uso das fontes no trabalho de pesquisa. A nova apreensão sobre o tempo histórico trazia à tona novos objetos e também o questionamento a fontes estáticas, arbitrárias. Um impulso ao uso de fontes diversas começou a despontar como basilar para se pensar na multiplicidade de novas abordagens propostas para a pesquisa histórica, onde não apenas o tempo era decomposto, mas também os elementos sociais, suas história cotidianas, os aspectos pouco percebidos ou que passariam desatentos ao olhar restrito a fontes documentais.

Mas os desafios não estão postos se o historiador se contenta apenas com os eventos dos vencedores, sem perceber na complexidade dos fatos e das múltiplas temporalidades quantos agentes sociais e condições diversas perfazem o emaranhado de elementos que se entrelaçam para o entendimento da sociedade no tempo. Nesta perspectiva Braudel enunciou que

aos historiadores é necessário ir pela contra-encosta, reagir contra as facilidades de seu mister, não estudar apenas o progresso, o movimento vencedor, mas também seu oposto, essa abundância de experiências 
contrárias que não foram quebradas sem dificuldades (BRAUDEL, op.cit., p. 117).

A historiografia dá voz aos vencidos quando entende que a História é construída e escrita em uma perspectiva dinâmica, quando percebe que o tecido social é formado a partir das variadas diferenças e que a História traduz esse movimento dialético que tece o diálogo entre a sociedade e o tempo. Uma perspectiva política da História consolidada ao longo do século XIX projetava não apenas a história dos vencedores, mas autorizava- se a ser a voz oficial sobre a história nacional, arvorava-se a porta voz dos épicos eventos nacionais para contá-los e torná-los as referências sociais e/ou nacionais que estabeleciam o elo entre a sociedade, o Estado, os governos e a construção de sua autoimagem.

Esses novos paradigmas indicaram o lugar ocupado pela pesquisa histórica no campo do conhecimento, mas também o debate interno que se faria presente, mesmo entre os Annales sobre as relações entre a História e sua interação com a construção política e social. Isso foi apontado por François Dosse quando criticou a rejeição do "político" pela revista, se recusando a atuar para que a Historiografia contribuísse para compreender as questões políticas contemporâneas dos anos 1940. Esse distanciamento autorizou também a subordinação da direção da revista à orientação dada pelas autoridades nazistas em certo momento (cf. DOSSE, op.cit., p. 61-70). A rejeição ao político, mas também a um determinado papel a ser ocupado pelo campo da pesquisa histórica, foram as opções que fizeram com que os Annales não tenham ocupado seu lugar no debate mais progressista na crítica ao fascismo e ao nazismo; isso foi posteriormente objeto de crítica do próprio Bloch quando avaliou que "nós não ousamos ser, na praça pública a voz que grita, a primeira vista no deserto (...) preferimos nosso confinamento na quietude temerosa de nossos escritórios" (BLOCH, 1946 apud DOSSE, op.cit., p. 62).

\section{O trabalho do Historiador}

A História como ciência nasce no século XIX, no âmago da emergência dos Estados Nacionais europeus e no momento em que se afirmava uma concepção de ciência. A Ciência nascida nos oitocentos refletia uma afirmação de determinadas áreas do conhecimento e na apropriação do conhecimento por determinados setores da 
sociedade. A ciência se tornava a porta-voz da verdade e de uma determinada percepção de mundo.

Do ponto de vista estritamente metodológico, isto é, das opções técnicas e dos demarcadores iniciais a serem selecionadas para a pesquisa e o ensino de História em Educação do Campo, pensamos em pautar nossa aproximação ao tema a partir de uma reflexão conceitual-operacional que obviamente não se esgotará nesta explicação, mas que deve fazer parte de toda investigação no campo acima descrito.

Como ponto de partida, é importante de início afastarmo-nos, ainda que temporariamente, do ponto de vista defendido por muitos sobre o papel da Memória, justapondo-se, e mesmo sobrepondo-se à ciência histórica (LOWENTHAL, 1998, p. 524). Não se quer aqui desvalorizar a importância da Memória Social para a organização social e, tampouco, para o Ensino de História, considerada

\footnotetext{
dimensão fundamental à definição de políticas de desenvolvimento local, na perspectiva de aprofundar o enraizamento/pertencimento destas comunidades como elemento constitutivo de um capital social potencializador das cadeias de reciprocidade, confiança, normas e sistemas de participação (TEIXEIRA et al., 2007, §7),
}

mas antes, destacar a importância da História como 'ciência dos homens no tempo', e do papel que a documentação, os vestígios materiais etc. ocupam na construção do objeto histórico a ser investigado. Os testemunhos vividos e os relatos correspondentes, ou a experiência sentida podem mesmo ocupar o centro da análise, mas são válidas como interpretação da realidade e não a realidade ela própria. No entanto, é importante apontar que as construções coletivas de representações do passado, das quais muitos historiadores se servem, estão em franco entrelaçamento com grupos sociais nos quais o próprio historiador toma parte, seja em dado momento, seja em dado lugar, ou em ambos. Este envolvimento possibilita influências recíprocas sem que se consiga delimitar o que é História e o que é Memória (social).

Dito isto, há que se perguntar em primeiro lugar das peculiaridades da Educação do Campo como campo de estudo pertinente, de suas particularidades e, finalmente, de como a ciência histórica interfere e auxilia no entendimento deste mesmo campo. Partimos do pressuposto, que obviamente se manifesta pelas condições em que este campo específico de estudo se desenvolve, de que a Educação do Campo implica e envolve uma área de análise ligada à educação rural (HOPFNER et al., 2011), sem com isso adentrarmos na difícil tarefa de definir o que se entende por Rural (WHITAKER, 1983, p. 72-76; cf. também ALPE et al., 2008). Stricto sensu, as relações das 
comunidades rurais se fundam nas relações com a terra e pressupõem o problema do acesso à terra. Ora, o acesso à terra, à matéria prima para a reprodução da vida comunitária no âmbito Rural tem que estar no horizonte desta discussão, mesmo que a luta pela terra deva ser superada em algum momento, para dar lugar ao debate em seus mais diferentes níveis de 'luta' (MALUF, 2007)'. Esta 'luta' pode se dar através do Esporte, da Arte, e não exclusivamente no âmbito da atividade produtiva, visando à distribuição de renda e a diminuição das disparidades sociais, mas é imperativo o aspecto do trabalho ligado a terra como processo coletivo e da ação comum, organizada. Isso implica também dizer que um dos aspectos essenciais na luta pela terra é a denúncia das várias formas de expropriação de bens, seja de recursos naturais, seja do homem pelo homem, ou seja, da Violência e de sua contra-parte a Resistência (LABICA, 2005). Para isso, aqui há que refletirmos, ainda que momentaneamente, sobre como estas formas se organizam na História, seus protagonistas, os elementos estruturantes que atuam de modo a conformar uma dada organização social. Este, pois, é um dos tópicos que merece um tratamento teórico-metodológico próprio na medida em que o conjunto de fontes, especialmente as escritas, que se nos oferecem, refletem comumente a visão do vencedor por se tratarem de formas de expressão restritas a classes sociais privilegiadas. Um rápido sobrevoo na História da luta social e das formas de exploração da terra pelos homens revela o quanto as fontes textuais podem nos proporcionar informações distorcidas, a começar pela transformação que as distintas formas de propriedade sofreram ao longo da história. Assim, por exemplo, contratos de compra e venda de terras, e obviamente das benfeitorias e de todo cabedal agregado (pomares, instrumentos agrícolas etc.), em diversos momentos da história encontrados em arquivos na Babilônia (REDE, 2007, p. 123-149), em registros fiscais medievais (FELLER, 1997, p. 147-164), ou em cartórios no Brasil do século XIX (MOTA, 2009), refletem o ponto de vista do comprador, isto do grupo que dispõe de recursos para a compra de propriedades e, consequentemente, com direitos de alienação de bens. Com isso, condicionado a um ponto de vista dos grupos dominantes, a partir de certa documentação fundiária e patrimonial, a pesquisa sobre um tema tão controverso quanto a mobilidade social no campo resulta bastante comprometida na medida em que cristaliza certo ponto de vista sobre a possibilidade ou impossibilidade de ascensão

\footnotetext{
${ }^{5} \mathrm{O}$ problema da pobreza rural é evidentemente bem mais abrangente e tem conseqüências sobre várias políticas sociais.
}

\begin{tabular}{|l|l|l|l|l|} 
Revista Dialectus & Ano 1 & n. 1 & Julho-Dezembro 2012 & p. 284-298 \\
\hline
\end{tabular} 
social e das formas em que ela se realiza, pois, porque não dizer, tal documentação reflete mesmo uma 'visão de mundo' (Weltanschauung), com sua linguagem própria, com sua mentalidade característica (Cf. BURGUIÈRE, 1982, p. 424-437). Como contraponto ao aparente engessamento social, a investigação voltada para as formas de resistência, os tipos de revolta social e de conflito social direto, bem como suas manifestações indiretas (festas populares, banditismo social etc.) são dignas de atenção para o historiador. Deste modo, o registro direto sobre a situação histórica em uma determinada comunidade, onde, aparentemente as relações sociais se expressam, por exemplo, de forma 'ordeira e pacífica' fica matizado - e consequentemente precisa ser repensado, no momento que nesta mesma localidade a violência, a insubordinação, a intolerância etc., também vêm à baila.

Como resultado, o tema da violência no campo, e da violência de um modo geral, ao longo da história tem se mostrado bastante fecundo para o pesquisador cujas pesquisas podem ser direcionadas à instrumentalização das forças do Estado ou dos grupos mais abastados para reprimirem ou enquadrarem os movimentos sociais. Obviamente, estamos tratando de apenas $\boldsymbol{u m}$ aspecto do tema: o do ponto de vista da objetividade. De uma perspectiva de caráter subjetivo, é possível discutir neste mesmo campo de análise as formas de servilismo, de contra-cultura, ou de uma interpretação conjuntural e funcional da sociedade, e até mesmo como tais temas são tratados historiografia, isto é, uma metahistória. Ora, neste ponto da investigação, as sínteses, a visão da totalidade (ou do todo social), e fundamentalmente o pressuposto das múltiplas temporalidades, já citadas, possuem um papel decisivo para a análise. Isto porque entram em jogo, e porque não dizer, em embate, as diversas modalidades de abordagens que privilegiam o particular em detrimento do geral, o fragmentário em lugar das totalidades, o palpável em substituição ao abstrato e aos silêncios, o individual acima e à parte dos sujeitos coletivos, reduzindo nosso campo de visão para uma História unilinear, monocausal e etapista.

Isso nos conduz ao outro ponto igualmente importante para a discussão da História: a questão do Progresso. Aqui, como em outros pontos brevemente tratados, o tema deve adquirir uma conformação tanto descritiva quanto normativa. Por um lado, volta-se a pesquisa ao debate de como os distintos grupos sociais, comunidades, nações se diferenciam umas das outras no diz respeito a sua existência material; por outro lado, abre-se uma possibilidade de análise onde as questões de "avanço-atraso", "progressodesenvolvimento" e outros temas relacionados apresentam-se como centrais (NISBET, 
1985; KENNEDY, 1989; HUNTIGTON, 1997) ${ }^{6}$. Tanto no seu campo objetivo de análise, isto é, o da Educação ou do processo de formação, do uso da tecnologia etc., que aparecem como sinônimo de progressivo bem estar dos povos, e por tabela de melhoria das condições de vida, quanto em sua dimensão subjetiva e mais abstrata, a saber, aquela das transformações necessárias no decorrer do tempo para a existência do todo social, o tema do Progresso em História reserva uma abundância de problemas para o pesquisador. Aqui, a literatura é abundante e, para o que nos interessa, limitar-nos- emos a tratar apenas do tema sucintamente. Por muito tempo, várias correntes de pensamento, entre elas o marxismo, se debruçaram sobre uma imagem romântica da noção de Progresso, associando-o diretamente à Tecnologia e reificação do Homem, responsável por um “desencantamento" do mundo (Cf. BERMAN, 1986). Os liberais e os neoliberais contraatacavam afirmando exatamente o contrário. Afirmavam que o progresso "libertou as energias mais positivas", constitutivas do Homem (LANDES, 2005, passim). Do ponto de vista da noção de Progresso o problema deve ser enfrentado em seu próprio campo de batalha, a saber a sociedade tecnológica, apresentando-a como uma construção histórica, humana (e não providencial, irrefreável ou irresistível da roda da história), tão válida quanto qualquer outra em seus avanços e recuos. A nosso ver, deve ser uma preocupação da Teoria da História para uma Educação de Campo. Na cidade, com suas favelas, lixo, desorganização urbana etc., este traço é facilmente reconhecível mas no campo não o é. Há um perigo teórico aqui: a de que não o tempo histórico não deva ser considerado como real, e sim como uma construção mental, que sobrevoa nossas cabeças. Por isso, os aspectos temporais, a discussão sobre longa duração e curta duração tem que estar no interior da discussão desta noção.

Então, acreditamos que boa parte da reflexão sobre a especificidade desta área de investigação deve reconhecer a dicotomia existente, no tempo e no espaço, entre campo e cidade, e para além desta entre o urbano e o rural, entre o centro e a periferia, entre o interior e o citadino, o nacional e o forâneo etc. Ao longo da história, e considerando as especificidades de cada região do globo, o entendimento sobre a relação entre campo e cidade deixa de constituir mero elemento operacionalizador das questões sobre o funcionamento das sociedades e dos movimentos para alcançar o status de hipótese geral sobre a existência mesma destas sociedades, suas formas de

\footnotetext{
${ }^{6}$ Os três, com claras inclinações a correntes do pensamento liberal, suscitaram, na época, um enorme debate e lançam mão recorrentemente de argumentos sobre superioridade tecnológica (ou da razão) do ocidente.
} 
(re)produção, conflitos e resistências. Em tempos de globalização estes conceitos Campo e Cidade - ganharam uma re-significação, cujo efeito provisório é uma nova fase do Capital, e que não afastaram o processo de exclusão e reprodução das hierarquias sociais, e que pretendem criar novos laços, de modo assimétrico, de (mútua) dependência. Ora o desafio que se faz presente é entender e enfrentar os processos que desagregam o tecido social constituído em um ambiente onde os laços sociais e as relações coletivas de trabalho se edificaram, em oposição aquele da cidade onde o indivíduo é o foco da Educação e do processo formador. É preciso lembrar que, no campo, o papel da comunidade tem peso considerável sobre as ações dos indivíduos e as ramificações que supõem certo aparato de controle social são bem mais extensas que em espaços densamente povoados. Por isso, um outro aspecto importantíssimo e que é parte desta discussão teórica é a noção de espaço histórico. Aqui retornamos às preocupações de Braudel e de tantos outros (LEFEBVRE, 1991), com farta bibliografia sobre as relações entre tempo e espaço e a necessidade de estudarmos um espaço socialmente construído.

\begin{abstract}
A distinção sistemática de diferentes níveis de análise espaço-temporais não é somente indispensável, hoje, na pesquisa de alto nível; ela o é, talvez mais ainda, na prática pedagógica: salta-se, bem freqüentemente, e sem precaução, considerações planetárias (o Terceiro Mundo), a exemplo de tal aldeia ou de evoluções seculares (a "revolução industrial") na narração de determinado acontecimento capital que não durou, no entanto, mais do que algumas horas (LACOSTE, 1988, p. 124).
\end{abstract}

A análise do espaço, homologamente à análise do tempo, deve reconhecer os distintos níveis espaciais, e suas correspondentes históricas, articulando-os, explicitando caráter artificial, interpretativo e humano dos recortes espaciais, que a exemplo dos recortes temporais, possuem tanto uma realidade material como também simbólica (HAESBAERT, 2005).

\title{
Considerações Finais
}

O processo de escolarização e seus desdobramentos têm um efeito sobre as comunidades rurais como reorganizadores da vida social porque a procura por educação muitas vezes significa migração, diminuição da força da mão de obra nas áreas de origem etc. Então um dos desafios é a fixação do homem a terra e ao mesmo tempo a sua inserção no mundo, e não o seu isolamento (por isso a tônica no processo como algo coletivo). A dicotomia campo $X$ cidade se apresentou na História como um processo de 
separação de ambas as partes e que agora, o novo processo de divisão internacional do trabalho chamado globalização, com o predomínio de grandes centros financeiros, busca atrair para sua própria órbita o campo. Os grupos sociais residentes no campo se inserem de um modo muito particular no processo de divisão internacional do trabalho, tendo, em não poucos casos, como única alternativa para integrar-se, a internet e os meios eletrônicos. Com isso, entre outros efeitos, ele dilui sua identidade e ganha uma nova. Este processo de transformação é bastante recente e tem um lastro histórico que o explica em parte.

Cremos que o ensino da História, em seus níveis objetivos e subjetivos, podem contribuir para o que é chamado de Identidade Social (WOODS, 2008). Antes de mais nada, a possibilidade de lidarmos com o passado, recente ou muitíssimo longínquo, amplia nossa capacidade de lidar com o outro, vê-lo como igual, naquilo que, no limite, é a sua humanidade, mas que pode incluir aspectos econômicos, sociais, jurídicos etc., mas, simultaneamente, diferente, no que tange não apenas a(s) sua(s) história(s) pessoal(is) mas na construção de sua(s) memória(s) coletiva(s), proporcionando-lhe(s), por assim dizer, 'raízes"7.

\section{Referências Bibliografia:}

ALPE, Y.; FAUGUET, J.-L. Enseigner dans le rural : un « métier » à part ? In: Travail et formation en éducation, n. 2, 2008. Disponível em: http://tfe.revues.org/index767.html. Acesso em 05 de Nov. 2012.

BERMAN, Marshall. Tudo que é sólido se desmancha no ar. A aventura da modernidade. Trad. C. F. Moisés e A. M. L. Ioriatti; M. Macca (notas). São Paulo: Cia das Letras, 1986.

BLOCH, Marc. L'Etrange défaite. Paris: Ed. Francs-Tireus, 1946.

Apologia da história ou o Ofício do Historiador. Edição anotada por Étienne Bloch. Trad. André Telles. Rio de Janeiro: Jorge Zahar Ed. 2001.

BURGuiÈre, André. The Fate of the History of Mentalité in the Annales. In: Comparative Studies in Society and History. Volume 24, Issue 03, Julho de 1982, p. 424437.

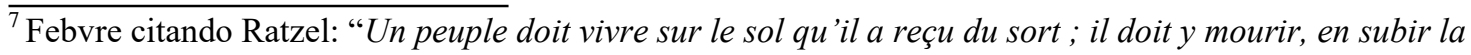
loi”. (FEBVRE, 1949, p. 420).
} 
BURKE, Peter. A Escola dos Annales: 1929-1989. A Revolução Francesa da Historiografia. Trad. Nilo Odalia. São Paulo: Fundação Editora da UNESP, 1997.

DOSSE, François. A História em Migalhas: Dos Annales à Nova História. Trad. Dulce Ramos. São Paulo: Ensaio/Campinas: Editora da Unicamp, 1992.

FEBVRE, L. La Terre et L'Évolution Humaine. Introduction Géographique a L'Histoire. Paris: A. Michel, 1949.

FELLER, L. Statut de la terre et statut des personnes. La thématique de l'alleu paysan dans l'historiographie depuis Georges Duby. In: Études Rurales, 1997, p. 147$164 . \quad$ Disponível em: http://hal.archivesouvertes.fr/docs/00/07/73/23/PDF/ALLEU3.pdf. Acesso em 05 de Nov. 2012.

HAESBAERT, Rogerio. Da Desterritorialização à Multiterritorialidade. In: Anais do $X$ Encontro de Geógrafos da América Latina - 20 a 26 de março de 2005. USP.

HOPFNER, J. (org.). Erziehung und Bildung in ländlichen Regionen. Frankfurt: Peter Lang, 2011.

HUNTIGTON, Samuel P. O Choque de Civilizações e a Recomposição da Ordem Mundial. Trad. M. H. C. Cortês. Rio de Janeiro: Ed. Objetiva, 1997.

KENNEDY, Paul. Ascensão e Queda das Grandes Potências. Rio de Janeiro:

Campus, 1989.

LABICA, Georges. Pour une théorie de la violence. [On line]. Disponível em: http://lahaine.org/labica/b2-img/labica_violence_01.pdf. Acesso em 01 Nov. 2012.

LACOSTE, Yves. A GEOGRAFIA. Isso Serve em Primeiro Lugar para Fazer a Guerra. Trad. de M. C. França. Campinas: Editora Papirus, 1988.

LANDES, D. Prometeu Desacorrentado. Transformação Tecnológica e Desenvolvimento Industrial na Europa Ocidental, de 1750 até os dias atuais. Trad. M. R. Motta. Rio de Janeiro: ElsevierlCampus, 2005.

LEFEBVRE, Henri. The Production of Space. Trad. D. Nicholson-Smith. USA/UK/Austrália: Basil Blackwell, 1991.

LOWENTHAL, David. Fabricating Heritage. In: History and Memory. Vol. 10, n. 01, 1998, p. 5-24.

MALUF, R. S.; BURLANDY, L. Poverty, Inequality and Social Policies in Brazil. Centro de Referência em Segurança Alimentar e Nutricional (CERESAN). Rio de

\begin{tabular}{|l|l|l|l|l|} 
Revista Dialectus & Ano 1 & n. 1 & Julho-Dezembro 2012 & p. 284-298 \\
\hline
\end{tabular}


Janeiro. 2007. p.1-45. Disponível em: http://r1.ufrrj.br/cpda/ceresan/docs/tx_disc_vs_ingles.pdf. Acesso em 05 de Nov. 2012.

MOTA, M. S. C. Nas Terras de Guaratiba. Uma Aproximação Histórica-Jurídica às Definições de Posse e Propriedade da Terra no Brasil entre os Séculos XVI-XIX. Tese de Doutorado. Rio de Janeiro. CPDA. UFRRJ. 2009.

NISBET, Robert. História da Idéia de Progresso. Trad. L. J. C. Jobim. Brasília: Ed. UnB, 1985.

REDE, M. Preservar e resistir: padrões de alienação de imóveis no período babilônico antigo. In: Revista Tempo. Vol. 12, n. 23, 2007, p. 123-149.

REIS, José Carlos. Nouvelle Histoire e o Tempo Histórico. A contribuição de Febvre, Bloch e Braudel. $2^{\mathrm{a}}$ ed. São Paulo: Annablume, 2008.

STOIANOVICH, Traian. French Historical Method: The Annales Paradigm. Ithaca: Cornell Univ. Press, 1976.

TEIXEIRA, A. M. F.; FREIXO, A. A.; LARANJEIRA, D. H. P. Memórias do rural e educação do campo: um encontro entre os "velhos" e os "moços" do semi-árido baiano. In: Encontro de Pesquisa em Educação do Norte e Nordeste. Maceió. Anais. Maceió: EdUFAL, 2007.

WHITAKER, W. H. Conceptualizing "Rural" for Research in Education: A Sociological Perspective. In: Journal of Research in Rural Education. Vol. 1, n. 02, 1983, p. 71-76.

WOOD, Ellen. A origem do capitalismo. Trad. Vera Ribeiro. Rio de Janeiro: Jorge Zahar Ed., 2001.

WOODS, M. Social Mouvements and Rural Politics. In: Journal of Rural Studies. Vol. 24, n. 02, 2008, 129-137. 